\title{
Aplikasi Pengenalan Hewan dengan Teknologi Marker Less Augmented Reality Berbasis Android
}

\author{
Aldi Apriansyah ${ }^{1}$, Dhimas Mulia Anugraha², Galuh Prakoso ${ }^{3}$, Kevin Nuardy Erdiham $^{4}$, Rudi \\ Priyana $^{5}$ \\ Program Studi S1Teknik Informatika Universitas Nasional \\ 1aldiaprian17@gmail.com, ${ }^{2}$ dhimas12ia1@gmail.com, ${ }^{3}$ galuhprakoso17@gmail.com, \\ kvinerdiham@gmail.com, ${ }^{5}$ rudiepriana@gmail.com
}

\begin{abstract}
Along with rapid technological developments, technological developments also affect in the field of education. But not yet used in the field of education that requires props, for example the introduction of animals at an early age. Currently the introduction of animals at an early age is still in the form of drawings and explanations described by a teacher, some are using props, but the number of props is limited, especially teachers difficulties in preparing the learning system for having to carry the props. With Augmented Reality supported by marker less method. Users do not need special black-and-white marker, but use 2D images presented in the form of magic book by the author as a reference book to release 3D content, and the procurement of virtual buttons and sounds in each animal. That way the learning process will be more effective and maximal. In this study used several devices with different specifications to test whether this application can run well in every device or not. From the results of research that marker can be read with kamerasmartphone with response time to detect marker approximately 1 second. The minimum distance of the marker detection is approximately $8-12 \mathrm{~cm}$ and the maximum distance is approximately $100-140 \mathrm{~cm}$. For an optimal distance of approximately $30 \mathrm{~cm}$. The minimum angle for marker detection is $45^{\circ}$ and a maximum angle of $170^{\circ}$. For optimal sudit approximately 50

-65 . Displays a virtual button in the target image scene and comes with sound generated from the 3D model.
\end{abstract}

Keywords : Animal Introduction, Augmented Reality, Marker Less, Android, Vuforia

\begin{abstract}
Abstrak
Seiring perkembangan teknologi yang pesat, perkembangan teknologi juga mempengaruhi dalam bidang pendidikan. Namun belum terlalu dimanfaatkan dalam bidang pendidikan yang membutuhkan alat peraga, contohnya pengenalan hewan pada usia dini. Saat ini pengenalan hewan pada usia dini masih berbentuk gambar dan penjelasan yang dijelaskan oleh seorang pengajar, ada pula yang menggunakan alat peraga, namun alat peraga jumlahnya terbatas, terlebih lagi pengajar kesulitan dalam mempersiapkan sistem pembelajaran karena harus membawa alat peraga tersebut. Dengan adanya Augmented Reality yang didukung dengan metode marker less. Pengguna tidak memerlukan marker khusus berbentuk hitam putih, melainkan menggunakan gambar 2D yang disajikan dalam bentuk magic book oleh penulis sebagai buku acuan untuk mengeluarkan konten berbentuk 3D, serta pengadaan virtual button dan suara pada masing-masing hewan. Dengan begitu proses pembelajaran akan lebih efektif dan maksimal. Dalam penelitian ini digunakan beberapa perangkat dengan spesifikasi yang berbeda untuk menguji apakah aplikasi ini dapat berjalan dengan baik di setiap perangkat atau tidak.Dari hasil penelitian bahwa marker dapat dibaca dengan kamerasmartphone dengan waktu respon untuk mendeteksi marker kurang lebih 1 detik. Jarak minimum pendeteksian marker kurang lebih 8-12 cm dan jarak maksimum kurang lebih 100-140 cm. Untuk jarak optimal kurang lebih $30 \mathrm{~cm}$. Sudut minimum untuk pendeteksian marker sebesar $45^{\circ}$ dan sudut maksimum $170^{\circ}$. Untuk sudit optimal kurang lebih $50^{\circ}-65^{\circ}$. Menampilkan virtual button dalam scene image target dan dilengkapi dengan suara yang dihasilkan dari model 3D.
\end{abstract}

Kata kunci : Pengenalan Hewan, Augmented Reality, Marker less, Android, Vuforia 


\section{PENDAHULUAN}

Pendidikan merupakan hal yang penting bagi pembentukan pribadi dan karakter manusia, pemberian pendidikan sejak dini menjadi faktor penting dalam pembentukan pribadi dan karekter. Di sekolah, proses pembelajaran pada umumnya hampir sama, yaitu adanya guru sebagai pengajar dan pemberi materi, alat penjelasan dan peraga seperti papan tulis, buku bergambar dan lain sebagainya untuk memperjelas proses pembelajaran.

Augmented reality merupakan teknologi yang menggabungkan benda maya dua dimensi maupun tiga dimensi ke dalam sebuah lingkungan nyata lalu memproyeksikan benda-benda maya tersebut dalam waktu nyata (real time).AR dapat juga didefinisikan sebagai teknologi yang mampu menggabungkan objek maya dalam dua dimensi (2D) dan tiga dimensi (3D) ke dalam sebuah lingkungan nyata, kemudian memproyeksikan objek-objek tersebut secara real time.Augmented Reality (AR) menggabungkan dunia nyata dengan dunia virtual. Augmented Reality (AR) hanya menambahkan serta melengkapi kenyataan berbeda dengan realitas maya yang menggantikan kenyataan sepenuhnya ${ }^{[5]}$.

Dengan adanya masalah yang dihadapi pada pembelajaran interaktif pada pengenalan hewan yang kurang efektif. Dimana pengenalan hewan hanya dengan menggunakan gambar saja ,maka dibutuhkannya sebuah aplikasi augmented reality untuk mempermudah anak dapat memvisualisasikan dan berinteraksi secara lebih nyata.

Penelitian ini menggunakan metode Marker less. Teknik Marker less menggunakan vuforia dan QCAR (Qualcom Augmented reality) yaitu memungkinkan objek yang berupa citra maya 3D maupun 2D muncul pada layar perangkat android yang ditangkap oleh kamera.

\section{METODE PENELITIAN \\ Flowchart Aplikasi Augmented Reality}

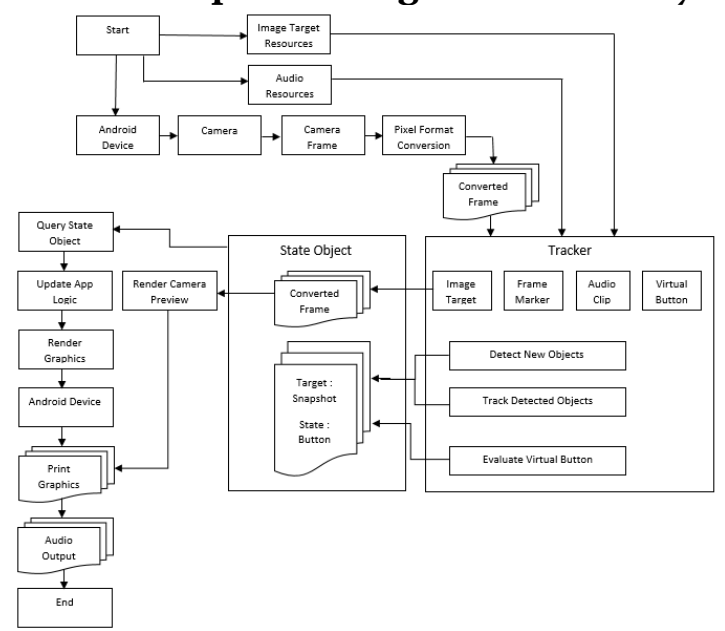

Gambar 1. Flowchart Sistem Aplikasi Marker less

Penjelasan:

1. Target resource memiliki data berupa objek 2D dan objek 3D berdasarkan database dari vuforia dan model 3D yang telah dibuat sebelumnya.

2. Perangkat android menangkap frame melalui kamera dan diteruskan untuk dikonversi menjadi frame ARcamera.

3. Karena menggunakan metode marker less, maka menggunakan metode track able target untuk memunculkan objek 3D.

4. Setelah objek terdeteksi melalui proses framing, dilakukan konversi melalui state objek, dimunculkan sebagai keluaran pada perangkat android.

5. Audio resource memiliki data yang berupa audio yang digunakan sebagai media untuk membawa unsur bunyi dari setiap objek 3D yang muncul dalam kamera smartphone.

\section{Design User Interface}

Concept Art adalah desain yang akan menjadi referensi perancangan aplikasi augmented reality pengenalan hewan, maka dibutuhkan perancangan konsep,sketsa atau objek yang dibutuhkan sebelum memasuki tahap produksi aplikasi. 
1. Tampilan Antarmuka

Tampilan antarmuka di desain dengan simpel yang berfungsi untuk memudahkan user menggunakan aplikasi Mengenal hewan.

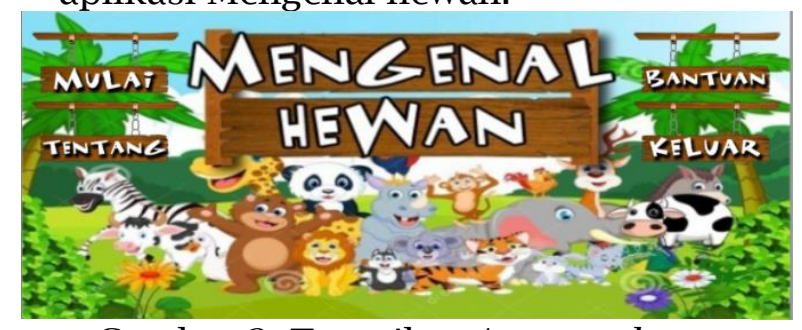

Gambar 2. Tampilan Antarmuka

2. Tampilan Menu Tentang

Menu tentang berisi informasi aplikasi Mengenal Hewan misalnya nama pembuat aplikasi.

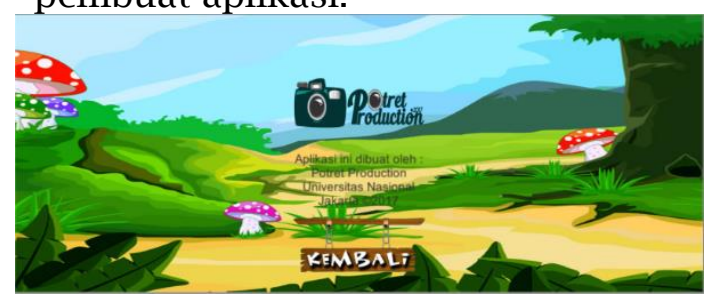

Gambar 3.Tampilan Menu Tentang

3. Tampilan Menu Bantuan

Menu bantuan berisi penjelasan penggunaan aplikasi Mengenal Hewan.

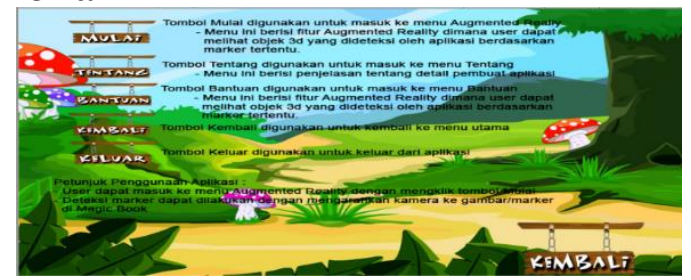

Gambar 4.Tampilan Menu Bantuan

4. Tampilan Menu Mulai

Menu yang menunjukkan saat proses scan image target berlangsung.

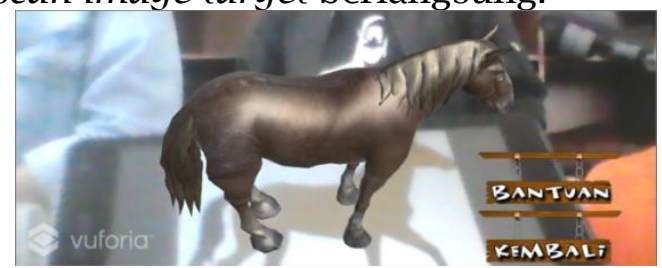

Gambar 5. Tampilan Menu Mulai

\section{HASIL DAN PEMBAHASAN \\ Perancangan}

Cara kerja implementasi teknologi augmented reality menggunakan Marker less dimana inputan berupa kamera smartphone yang akan mendeteksi marker hewan dalam magic book. Setiap marker akan memuncukan objek 3D sesuai marker yang dideteksi. Program akan load objek 3D sesuai dengan marker . Output yang didapat dari hasil proses kemudian akan ditampilkan pada layar smartphone.

Perancangan awal yang dilakukan dalam penelitian ini adalah perancangan marker yang menghasilkan rating tertinggi dalam vuforia.Marker yang digunakan harus mempunyai rating minimal tiga bintang karena berpegaruh terhadap perangkat dalam mengenali marker.Semakin bintangnya banyak, maka akan dengan mudah marker dikenali kamera smartphone. Selajutnya membuat sebuah model 3D yang hampir sama dengan gambar aslinya sehingga dapat menarik pengguna yang melihat.

Selanjutnya adalah tahapan proses. Penelitian ini menggunakan kamera smartphone Samsung Grand Prime 8 Mega Pixel, Samsung J1 Ace 5 Mega Pixel ,Vivo Y21 8 Mega Pixel dan Samsung Galaxy Tab A.80 5 Mega Pixel. Kamera akan membaca/track marker yang telah disimpan dalam sistem. Kemudian sistem akan me-load model 3D yang sesuai dengan marker dan kemudian akan dimuncukan dalam bentuk 3D. File model 3D yang dideteksi adalah file 3D yang mempunyai ekstensi .obj dan .blend.

\section{Tabel 1. Data rating marker}

\begin{tabular}{|c|c|c|c|}
\hline Marker & Nama & Rating & Status \\
\hline & Sapi & 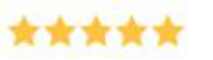 & Active \\
\hline & Kuda & 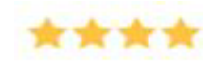 & Active \\
\hline & Serigala & 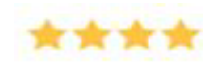 & Active \\
\hline & Zebra & तो th th & Active \\
\hline & Domba & $\Delta * t$ t & Active \\
\hline & Bebek & 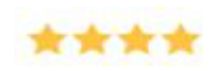 & Active \\
\hline & Gorilla & 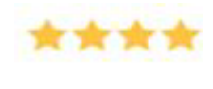 & Active \\
\hline
\end{tabular}




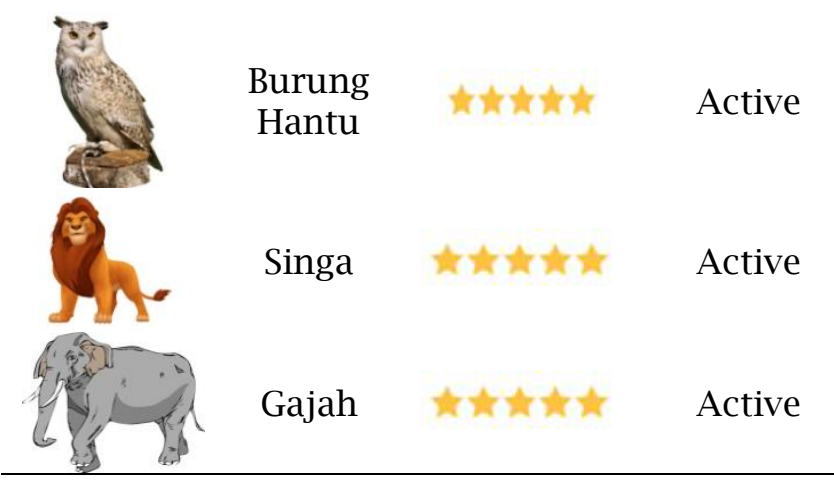

\section{Hasil Pembahasan}

Pengujian pendeteksian marker dengan menentukan waktu respon, jarak minimum dan sudut minimum.

1. Spesifikasi perangkat

Dalam pengujian ini diperlukan beberapa perangkat keras yang digunakan untuk melalukakan perbandingan dalam hal pendeteksian marker.

Tabel 2. Spesifikasi perangkat

\begin{tabular}{|c|c|c|c|}
\hline $\begin{array}{c}\text { Nama } \\
\text { Perangkat }\end{array}$ & $\begin{array}{c}\text { Versi } \\
\text { Android }\end{array}$ & RAM & Kamera \\
\hline $\begin{array}{l}\text { Samsung } \\
\text { Grand } \\
\text { Prime }\end{array}$ & Kitkat 4.4.4 & $1 \mathrm{~GB}$ & $8 \mathrm{MP}$ \\
\hline $\begin{array}{l}\text { Prime } \\
\text { Samsung } \\
\text { J1 Ace }\end{array}$ & Kitkat 4.4 .4 & $\begin{array}{l}768 \\
\mathrm{MB}\end{array}$ & $5 \mathrm{MP}$ \\
\hline $\begin{array}{l}\text { Vivo Y21 } \\
\text { Samsung }\end{array}$ & Lolipop 5.1 & $1 \mathrm{~GB}$ & $8 \mathrm{MP}$ \\
\hline $\begin{array}{l}\text { Galaxy } \\
\text { Tab A } 8.0\end{array}$ & $\begin{array}{l}\text { Marshmallow } \\
6.0 .1\end{array}$ & $2 \mathrm{~GB}$ & $5 \mathrm{MP}$ \\
\hline
\end{tabular}

2. Waktu respon

Pengujian ini dilakukan untuk menentukan waktu proses dalam pendeteksian marker Sebelum mengenali image target ketika kamera smartphone diarahkan ke marker pertama kali.

Tabel 3. Pendeteksian waktu respon

\begin{tabular}{cc}
\hline Perangkat & Waktu \\
\hline Samsung Grand & 1 detik \\
Prime & 1 detik \\
Samsung J1 Ace & 1 detik \\
Vivo Y21 & 1 detik \\
Samsung Galaxy Tab & \\
A 8.0 &
\end{tabular}

3. Jarak

Pengujian ini dilakukan dengan mengarahkan kamera smartphone pada jarak minimum dalam pendeteksian marker. Sehingga dapat menetapkan batas antara kamera smartphone ke image target dalam pendeteksian marker.

Tabel 4. Pendeteksian jarak minimum

\begin{tabular}{cccc}
\hline Perangkat & $\begin{array}{c}\text { Jarak } \\
\text { Minimum }\end{array}$ & $\begin{array}{c}\text { Jarak } \\
\text { Maksimum }\end{array}$ & $\begin{array}{c}\text { Jarak } \\
\text { Optimal }\end{array}$ \\
\hline Samsung & & & \\
Grand & $\pm 8 \mathrm{~cm}$ & $\pm 110 \mathrm{~cm}$ & $\pm 30 \mathrm{~cm}$ \\
Prime & & & \\
Samsung & $\pm 10 \mathrm{~cm}$ & $\pm 130 \mathrm{~cm}$ & $\pm 30 \mathrm{~cm}$ \\
J1 Ace & & & \\
Vivo Y21 & $\pm 10 \mathrm{~cm}$ & $\pm 135 \mathrm{~cm}$ & $\pm 30 \mathrm{~cm}$ \\
Samsung & & & \\
Galaxy & $\pm 12 \mathrm{~cm}$ & $\pm 140 \mathrm{~cm}$ & $\pm 30 \mathrm{~cm}$ \\
Tab A 8.0 & & & \\
\hline
\end{tabular}

4. Sudut minimum dan maksimum

Pengujian ini dilakukan untuk mengetahui sudut minimum dan maksimum dalam pendeteksian marker. Sehingga dapat memunculkan objek 3D dengan tepat.

Tabel 5. Pendeteksian sudut minimumdan maksimum

\begin{tabular}{lccc}
\hline Perangkat & $\begin{array}{c}\text { Sudut } \\
\text { Minimum }\end{array}$ & $\begin{array}{c}\text { Sudut } \\
\text { Maksimum }\end{array}$ & $\begin{array}{c}\text { Sudut } \\
\text { Optimal }\end{array}$ \\
\hline $\begin{array}{l}\text { Samsung } \\
\text { Grand }\end{array}$ & $45^{\circ}$ & $170^{\circ}$ & $50^{\circ}$ \\
$\begin{array}{l}\text { Prime } \\
\text { Samsung }\end{array}$ & $45^{\circ}$ & $170^{\circ}$ & $50^{\circ}$ \\
J1 Ace & & $170^{\circ}$ & $60^{\circ}$ \\
$\begin{array}{l}\text { Vivo Y21 } \\
\text { Samsung }\end{array}$ & $45^{\circ}$ & $170^{\circ}$ & $65^{\circ}$ \\
$\begin{array}{l}\text { Galaxy } \\
\text { Tab A 8.0 }\end{array}$ & $45^{\circ}$ & & \\
\hline
\end{tabular}

\section{Kesimpulan}

Kesimpulan dari hasil implementasi dan pengujian aplikasi dengan menggunakan black box. Dengan hasil yang didapatkan dimana waktu respon untuk mendeteksi marker kurang lebih 1 detik. Jarak minimum pendeteksian marker kurang lebih $30 \mathrm{~cm}$ dan jarak maksimum kurang lebih $100 \mathrm{~cm}$. Sudut minimum untuk pendeteksian marker sebesar $45^{\circ}$ dan sudut maksimum $170^{\circ}$. Menampilkan virtual button dalam scene image target dan dilengkapi dengan suara yang dihasilkan dari model 3D. 


\section{Saran}

Dalam pembutan aplikasi ini tentunya masih banyak kekurangan, kekurangan tersebut yang bisa menjadi pertimbangan untuk melakukan pengembangan terhadap aplikasi selanjutnya. Adapun saran yang dapat disampaikan untuk sebagai berikut:

1. Penambahan jumlah hewan yang dikenal agar lebih banyak

2. Menu detail yang terpisah mengenai jenis-jenis hewan, seperti hewan darat, hewan laut dan hewan udara sehingga lebih jelas.

3. Kualitas render objek hewan 3D yang lebih baik dan mendetail

4. Pengembangan platform kedepannya dapat diimpementasikan dalam platform Windows Phone, Ios maupun ke dalam web.

\section{DAFTAR PUSTAKA}

I Dewa Gede Wahya Dhiyatmaka, I Ketut Gede Darma Putra,NI Made Ika Marini Mandenni. 2015 .'Aplikasi Augmented Reality Magic Book Pengenalan Binatang Untuk Siswa TK" Lontar Komputer Vol 6 No 2. ISSN 2088-1541.
Muhammad Qori' Untiarasani, Hanny Haryanto, Erna Zuni Astuti. 2015. "Pembangunan Perangkat Lunak Interaktif berbasis Marker less Augmented Reality Untuk Pengenalan Hewan Pada Taman Kanak-Kanak ". Techno.com.Vol 14 No 2.

Nia Saurina. 2016 . "Pengembangan Media Pembelajaran untuk Anak Usia Dini Menggunakan Augmented Reality.".Jurnal IPTEK. Vol 20 No 1. ISSN 1411-7010.

Riana Indriani,Bayu Sugiharto,Agus Purwanto. "Pembuatan Augmented Reality Tentang Pengenalan Hewan Untuk Anak Usia Dini Berbasis Android Menggunakan Metode Marker less Vuforia.”. ISSN 2302-3805.

Sheila Claudy Riady, Steven Sentinuwo, Stanley

Karouw. 2016."Rancang Bangun Aplikasi Mobile Learning Anak Sekolah Minggu dengan Teknologi Augmented Reality Berbasis Androoid.". Teknik Informatika. Vol 9 No 1. 